\title{
Think About the Application of Vitamin E to Heterozygous Familial Hypobetalipoproteinemia to Prevent Liver Cirrhosis and Hepatocellular Carcinoma
}

\author{
Hidekatsu Yanai
}

Familial hypobetalipoproteinemia (FHBL) is a rare genetic disease characterized by low levels of low-density lipoprotein (LDL) cholesterol and apolipoprotein (apo) B. In homozygous FHBL, dietary fat restriction and long-term high-dose vitamin $\mathrm{E}$ and A supplementation are recommended to prevent the progression of neuromuscular and retinal degenerative disease [1]. However, it has been considered that heterozygous FHBL subjects are usually asymptomatic, and do not require vitamin E supplementation [1]. The accumulated literatures suggest the development of fatty liver diseases including non-alcoholic steatohepatitis (NASH)-related cirrhosis and hepatocellular carcinoma (HCC) in heterozygous FHBL individuals [1-11].

A 33-year-old skinny man was referred to me for the treatment of heterozygous FHBL. He had been diagnosed to have fatty liver disease and heterozygous FHBL 6 years ago. However, he was told that there was no treatment for FHBL by the doctor. His serum levels of total cholesterol, LDL-cholesterol and apo B (normal range: 73 - $109 \mathrm{mg} / \mathrm{dL}$ ) were 102, 27 and $22 \mathrm{mg} / \mathrm{dL}$, respectively, supporting the diagnosis of heterozygous FHBL. He complained of steatorrhea and general fatigue. I started the treatment using dairy $150 \mathrm{mg}$ of vitamin $\mathrm{E}$, which ameliorated steatorrhea and general fatigue. He gained body weight by $3 \mathrm{~kg}$. His father was diagnosed to have HCC when he was 63 years old; however, hepatitis $\mathrm{B}$ and $\mathrm{C}$ viruses, and alcoholism were not detected, suggesting the development of $\mathrm{HCC}$ due to NASH.

Vitamin E supplementation has been recommended for persons with homozygous FHBL because this disease leads to low serum lipid-soluble vitamin E. However, it has not been recommended that persons with heterozygous FHBL receive vitamin E supplementation [1, 12]. I think that a significance of vitamin $\mathrm{E}$ for fatty liver diseases including NASH, liver cirrhosis and HCC in heterozygous FHBL individuals has been forgotten. To our knowledge, there are no literatures about the application of vitamin E to prevent NASH in heterozygous FHBL. The efficacy of vitamin $\mathrm{E}$ is reasonably well established in a selected group of patients with NASH, who are

Manuscript accepted for publication October 19, 2016

Department of Internal Medicine, National Center for Global Health and Medicine Kohnodai Hospital, 1-7-1 Kohnodai, Ichikawa, Chiba 272-0034, Japan. Email: dyanai@hospk.ncgm.go.jp

doi: http://dx.doi.org/10.14740/jem380w not FHBL patients [13]. To prevent NASH, liver cirrhosis and HCC, we should think about the application of vitamin $\mathrm{E}$ to heterozygous FHBL patients who may have low serum vitamin E levels and may be also prone to develop NASH.

\section{Conflicts of Interest}

The author declares that there are no conflicts of interest concerning this article.

\section{References}

1. Burnett JR, Hooper AJ. Vitamin E and oxidative stress in abetalipoproteinemia and familial hypobetalipoproteinemia. Free Radic Biol Med. 2015;88(Pt A):59-62.

2. Welty FK. Hypobetalipoproteinemia and abetalipoproteinemia. Curr Opin Lipidol. 2014;25(3):161-168.

3. Martin-Morales R, Garcia-Diaz JD, Tarugi P, GonzalezSantos P, Saavedra-Vallejo P, Magnolo L, Mesa-Latorre JM, et al. Familial hypobetalipoproteinemia: analysis of three Spanish cases with two new mutations in the APOB gene. Gene. 2013;531(1):92-96.

4. Harada N, Soejima Y, Taketomi A, Yoshizumi T, Uchiyama H, Ikegami T, Saibara T, et al. Recurrent familial hypobetalipoproteinemia-induced nonalcoholic fatty liver disease after living donor liver transplantation. Liver Transpl. 2009;15(7):806-809.

5. Di Leo E, Magnolo L, Pinotti E, Martini S, Cortella I, Vitturi N, Rabacchi C, et al. Functional analysis of two novel splice site mutations of APOB gene in familial hypobetalipoproteinemia. Mol Genet Metab. 2009;96(2):66-72.

6. Katsuda S, Kawashiri MA, Inazu A, Tada H, Tsuchida M, Kaneko Y, Nozue T, et al. Apolipoprotein B gene mutations and fatty liver in Japanese hypobetalipoproteinemia. Clin Chim Acta. 2009;399(1-2):64-68.

7. Sen D, Dagdelen S, Erbas T. Hepatosteatosis with hypobetalipoproteinemia. J Natl Med Assoc. 2007;99(3):284-286.

8. Whitfield AJ, Barrett PH, Robertson K, Havlat MF, van Bockxmeer FM, Burnett JR. Liver dysfunction and steatosis in familial hypobetalipoproteinemia. Clin Chem. 2005;51(1):266-269.

9. Tarugi P, Lonardo A, Gabelli C, Sala F, Ballarini G, Cor- 
tella I, Previato L, et al. Phenotypic expression of familial hypobetalipoproteinemia in three kindreds with mutations of apolipoprotein B gene. J Lipid Res. 2001;42(10):15521561.

10. Ahmed A, Keeffe EB. Asymptomatic elevation of aminotransferase levels and fatty liver secondary to heterozygous hypobetalipoproteinemia. Am J Gastroenterol. 1998;93(12):2598-2599.

11. Heeks LV, Hooper AJ, Adams LA, Robbins P, Barrett PH, van Bockxmeer FM, Burnett JR. Non-alcoholic steato- hepatitis-related cirrhosis in a patient with APOB L343V familial hypobetalipoproteinaemia. Clin Chim Acta. 2013;421:121-125.

12. Clarke MW, Hooper AJ, Headlam HA, Wu JH, Croft KD, Burnett JR. Assessment of tocopherol metabolism and oxidative stress in familial hypobetalipoproteinemia. Clin Chem. 2006;52(7):1339-1345.

13. Gawrieh S, Chalasani N. Pharmacotherapy for Nonalcoholic Fatty Liver Disease. Semin Liver Dis. 2015;35(3):338-348. 